\title{
The Challenges and Successes of Dealing with the COVID-19 Pandemic in India
}

\author{
Juhi Sharma' \\ Divakar Sharma $\mathbb{D}^{2,3}$ \\ Dileep Tiwari ${ }^{2}$ \\ Vaishali Vishwakarma ${ }^{4}$ \\ 'School of Basic and Applied Science, \\ Eklavya University, Damoh, M.P., 47066I, \\ India; ${ }^{2}$ Hericure Healthcare Pvt Ltd, \\ Pune, India; ${ }^{3}$ Department of \\ Microbiology, Maulana Azad Medical \\ College, New Delhi, I 10002, India; \\ ${ }^{4}$ St. Aloysius College, Jabalpur, 482002, \\ India
}

\begin{abstract}
As the infectivity of the SARS-CoV-2 virus is higher compared with other coronaviruses reported so far, so effective therapeutics and vaccines are the best way to control the proliferation of this infection The COVID-19 mortality rate is lower compared with other similar viral diseases such as severe acute respiratory Ssndrome (SARS) and Middle East respiratory syndrome (MERS). However, due to the evolution of SARS-CoV-2 mutants that are responsible for the subsequent waves, mortality due to COVID-19 has increased across the globe. Currently, the magnitude of SARS-CoV-2 infection is highly severe and is leading to a tremendously increased number of deaths globally. Scientists expect that SARS-CoV-2 has the potential to become a seasonal disease like influenza and may persist with humanity in the future. Currently, preventive strategies such as sanitation, social distancing, use of masks, potential chemotherapies (pathogen-centric and host-centric), and vaccines are the only option to fight against COVID-19. Many groups of Indian government-public private consortia had set up different strategies (development of multiple vaccines) for combat of this unique threat through stepssuch as an increase in vaccinations and sample testing per day. In this focused review, we have discussed the challenges faced and success stories employed to manage COVID-19.
\end{abstract}

Keywords: COVID-19, potential strategies, vaccines, varients, chemotherapy

\section{Introduction}

The World Health Organization (WHO) affirmed COVID-19 as a pandemic on 11 March 2020 but earlier to this the Chinese government confirmed the first outbreak of Coronavirus disease 2019 (COVID-19) in Wuhan on 31December 2019. The state-wise lockdown, which was imposed in India due to the second wave of the novel coronavirus pandemic, affected people belonging to every economic stratum. In India, till now (9 July 2021), there have been $30,752,950$ confirmed cases of COVID-19 with 405,939 deaths reported to the WHO. COVID-19 cases are rapidly rising globally of which the first case was registered on 21February 2020 in Italy. Meanwhile in India, case numbers have risen, and community transmission was officially declared by government in October 2020. Life is deeply affected by COVID-19 even for the ones who are not infected as isolation, contact restrictions and economic shutdown have changed the social and economic scenario of India. Vast populations and crowded settlements have increased the number of cases in China, Europe, USA and India. Countries with dense populations and robust travel history will increase the problem of decision-making authorities if testing is limited or disproportionate. The 
WHO has made projections of 3.5 beds per 1000 population ${ }^{1}$ but many countries have only 1.3 beds per 1000 population in hospitals which is again the concern of government. As the pandemic is growing in stages, this review assesses the prospects these stages might have on the Indian population as it highlights some key challenges for treatment and research related to antiviral drugs.

\section{COVID-I 9 Disease Concatenation}

Cases were initially spread by migrants, overseas visitors, and some others who were in contact with these infected persons, and to control this spread lockdowns were called by various countries including India. The situation seemed to be under control due to the lockdown, but due to a religious gathering in New Delhi, which led to the human-to-human transmission of COVID-19, a sudden horrific increase in COVID-19 cases occurred. Initially, most individuals who came into contact with such infected individuals were unaware of the effects of the virus in their bodies. To sustain the country's economy, unlocks were called by the Indian Government in multiple phases, therefore, the persons who were unaware that they were carrying the virus spread it many more healthy persons. However, preventive measures including social distancing, quarantine and isolation techniques had been taken globally and have proven effective in the absence of drug treatments and other approaches. Adults (ages 50 and over), and people with comorbidities can have higher chances of becoming severely ill with COVID-19 and contribute to the largest portion of all deaths worldwide among infected cases. ${ }^{2,3}$

In India, the overall numbers dying constantly increased, amongst them a lot of the demise circumstances pointed to a particular age-group of aged folks. ${ }^{4}$ In India, among the total COVID-19 cases $(30,752,950)$ and total deaths $(405,939)$ till 9 July $2021,90 \%$ were older than 40 years. Overall, people in the age group of 40 years and greater, have suffered the major impact of the current COVID-19 eruption and are more vulnerable. ${ }^{5,6}$ The massive loss of people in the workforce is likely to have devastating social and economic consequences.

\section{WHO Guidelines for Prevention/ Control of COVID 19}

- Maintain at least a one-metre distance between yourself and others to reduce the risk of infection when they cough, sneeze or speak. Maintain an even greater distance between yourself and others when indoors.

- Make wearing a mask a normal part of being around other people. The appropriate use, storage and cleaning or disposal is essential to make masks as effective as possible.

The basic measures adopted worldwide include maintenance of hand hygiene, avoiding close contact, using face masks, disinfection and monitoring health. ${ }^{7}$ The ongoing COVID-19 pandemic has once again brought the benefits of appropriate hand hygiene (hand washing and use of alcohol-based hand-sanitizers) to the centre stage. Since hand washing is not a feasible and available option at all times, the use of alcohol-based handsanitizers (hand rubs) has been recommended by health organizations, when hands are not visibly soiled. These sanitizers act as a powerful, fast acting and effective solution with broad antimicrobial range. ${ }^{7}$ Hands act as a medium for exchange of microbes between the organism and its environment. The skin of the hands harbours a variety of organisms ranging from commensal to potential pathogens. Therefore, adequate hand hygiene can greatly reduce disease transmission. The most commonly used agents for hand disinfection are hand-sanitizers. There are two major types of preparations available: alcohol-based and alcohol-free. The alcohol-based ones, known as alcohol-based hand rubs (ABHRs), typically have ethyl alcohol (ethanol), isopropanol, or n-propanol at concentrations between 60 to $95 \%$ alcohol. ${ }^{8}$ The alcohol-free preparations usually contain quaternary ammonium compounds (benzalkonium chloride or benzethonium chloride). However, these have been found to be less effective and have a risk of contributing to antimicrobial resistance (AMR), hence are not recommended by CDC.

\section{Potential Consequences of Excessive Use of Hand-Sanitizer to Control of COVIDI9}

The CDC has recommended the use of ABHRs and hand washing to fight the COVID-19 pandemic. This is due to the structural characteristics of coronaviruses, which are enveloped viruses with lipid bilayer and are easily inactivated by alcohol. A combination of factors such as inappropriate formulations, excessive/repeated usage of hand sanitizers during this pandemic will have far reaching consequences. 
These may range from emergence of situation like alcohol tolerance and antimicrobial resistance (AMR), disturbance of normal microflora, and product toxicity. Similar to antibiotics, excessive or repetitive application of alcohol through hand-sanitizers has the potential to act as a selection pressure for the emergence of new microbial species tolerant to high alcohol concentrations. ${ }^{9}$

Taking note of the repetitive use of ABHRs, Professor Tim Stinear from the Peter Doherty Institute for Infection and Immunity remarked

Anywhere we repeat a procedure over and over again, whether it's in a hospital or at home or anywhere else, you're giving bacteria an opportunity to adapt, because that's what they do, they mutate. The ones that survive the new environment better then go on to thrive.

He further added that the risk increases when appropriate guidelines are not followed. ${ }^{10}$

Eliminating the normal microflora of the skin by repeated use of hand-sanitizers may eventually deprive the skin of the protection offered by these commensals. Long term use of personal protective equipment along with frequent hand hygiene was responsible for high rate of skin damage in $97 \%$ of respondents while frequent hand hygiene was attributed with increased risk of hand skin damage. ${ }^{11}$

\section{Analysis of COVID I9 Situation and Envisage the Resurgence}

The world has joined hands with parallel efforts for the production of vaccines in opposition to COVID-19 pandemic.

\section{Steps Taken by Government to Conflict Pandemic Foot-Operated Washing Station Implemented at IAO}

A densely populated area like Ladakh has set an example for implementation in the "Guidelines for hygiene and sanitation during the era of COVID-19 pandemic" by setting up FootOperated Washing Station, implemented at the Indian Astronomical Observatory (IAO), Hanle. Having one of the world's highest located sites for optical, infrared and gammaray telescopes operated by the Indian Institute of Astrophysics (IIA), Bengaluru, $\mathrm{IAO}^{12}$ has one in all the world's highest set sites for optical, infrared and gamma-ray telescopes.

\section{Antiviral Nano-Coating and Nano-Based Material Proposal Invited by DST to Combat COVID-I 9}

Antiviral nano-coating and new nano-based material for use in Personal Protective Equipment (PPE) was invited by The Department of Science and Technology (DST) using the Science and Engineering Research Board (SERB) portal, scale up for which could be done by partnering industry or start-up. India could be supported greatly by such nano-coatings technology to fight against COVID-19 pandemic. N-95 respirator, PPEs kits and triple-layer medical masks could be prepared from antiviral nano-coatings for safeguarding healthcare workers. ${ }^{13}$

\section{Technology Development Board (TDB) Has Exponentially Raised the Production of COVID-I 9 Diagnostic Kits Through Financial Support}

Patients that showed flu-like symptoms was screened and detected for COVID-19 through indigenous company "Mylab Discovery Solutions" through the development of PCR-based molecular diagnostic kit.

TDB will try to boost the production process of kits so that present capacity could increase from 30,000 tests per day to one lakh tests per day. This automation by company could be achieved within the next few months. Considering the national emergency COVID-19 kit will be deployed by ICMR and CDSCO. ${ }^{14}$

\section{Herbal Hand-Sanitizer Developed by Scientists of National Botanical Research Institute (NBRI)}

As the demand increased, production of sanitizers have seen a boom amid coronavirus outbreak. Owing to which alcohol-based herbal sanitizer was developed by NBRI under Council of Scientific and Industrial Research (CSIR)-Aroma Mission as per the World Health Organisation (WHO) guidelines. Apart from having $60 \%$ of isopropyl alcohol for killing germs it has essential oil from Tulsi as natural antimicrobial agent. It is not only last for 25 minutes but also prevents skin from dehydrating. Herbal sanitizer has been found to be effective against the pathogen (Staphylococcus epidermidis $)^{15}$ 


\section{Indian Researchers to Go for the Clinical Trial of Sepsis Drug Against Novel Coronavirus}

The Council of Scientific and Industrial Research (CSIR) is leaving no stone unturned in the battle against novel coronavirus. Repurposing of existing drugs is one of the strategies deployed by CSIR. The Council is implementing this strategy by evaluating an existing drug (Sepsivac, that available commercially) that is used for treating gram-negative sepsis patients. Both Gramnegative sepsis patients and critically ill COVID-19 patients, exhibit the altered immune response and a massive change in the cytokine profiles. Cytokines are produced in response to an infection and they are essential for host defence against pathogens. There are six types of cytokines, which belong to different families and the mixtures of cytokines, called cytokine profiles. One of the significant contributors to death by COVID19, has shown the heightened immune response, called a cytokine storm. The immune system starts attacking both infected as well as uninfected cells and unable to discriminate between a friend and a foe, leading to tissue damage which resulting in sepsis. This drug (Sepsivac) modulates the immune system of the body and thereby inhibits the cytokine storm leading to reduced mortality and faster recovery. ${ }^{16}$

\section{Advisory for Use of Cartridge-Based Nucleic Acid Amplification Test (CBNAAT) Using Cepheid Xpert Xpress SARS-CoV-2}

ICMR releases advisory for use of Cartridge-based Nucleic Acid Amplification Test (CBNAAT) using Cepheid Xpert Xpress SARS-CoV-2, effective from 19 April 2020. ${ }^{17}$

\section{India's First Indigenous Antibody- Based Testing Kit for Coronavirus Testing}

India's first antibody-based testing kit was developed by NuLife Consultants and Distributors Pvt. Ltd, New Delhi which takes only fifteen minutes to yield accurate results. It is launched in two weeks and regular production has also started it was approved by the Indian Council of Medical Research (ICMR). ${ }^{18}$ The new finger prick kit will provide adequate access to cost-effective testing.

\section{India's First COVID-I 9 Home Screening Test Kit Launched by Bione}

Home screening test kit for COVID-19 was launched by Bione with easy-to-use kit displays after approval from the requisite medical regulatory authorities.

In a get through development, the Company has devised the screening kit which can provide respite from the impending fear of the contagion. It will foster timely detection of the disease while acting as a preventive tool for others in proximity to the user, by isolating the carrier immediately. The kit is priced between '2000-3000 depending upon the global supply, to increase its affordability for the masses. Under normal circumstances, the ready-to-use kits can be received within 2-3 days of placing the order at their platform. To initiate an effective screening tool for mass screening, the organisation is also in talks to provide bulk orders for early detection. ${ }^{19}$

\section{Drugs /Molecules Can Arrest COVID-I 9}

Against COVID-19 drugs and experimental molecule are being prepared. SARS-CoV-2 is a single stranded RNA enveloped virus. The angiotensin-converting enzyme 2 (ACE2) receptor of the host cell binds to the spike (S) protein of the viral structure. The host type 2 transmembrane serine protease, TMPRSS2 facilitates the $\mathrm{S}$ protein. ${ }^{20}$ Once the virus enters the host, it starts synthesizing RNA through its RNA dependent RNA polymerase enzyme, which is then translated to products. Structural proteins facilitate the assembly and release of viral particles. ${ }^{21,22}$

During viral life cycle, chemotherapy is available of various potential targets. There are many non-structural protein promising drug targets which resembles with other coronaviruses (SARS-CoV and MERS-CoV) such as 3-chymotrypsin like protease, papain like protease and RNA-dependent RNA polymerase. Various molecules and their targets are represented in Figure 1.

\section{Hydroxychloroquine (HCQ) andChloroquine (CQ)}

Chloroquine and hydroxychloroquine used in prevention and treatment of malaria and chronic inflammatory diseases such as systemic lupus erythematosus (SLE) and 


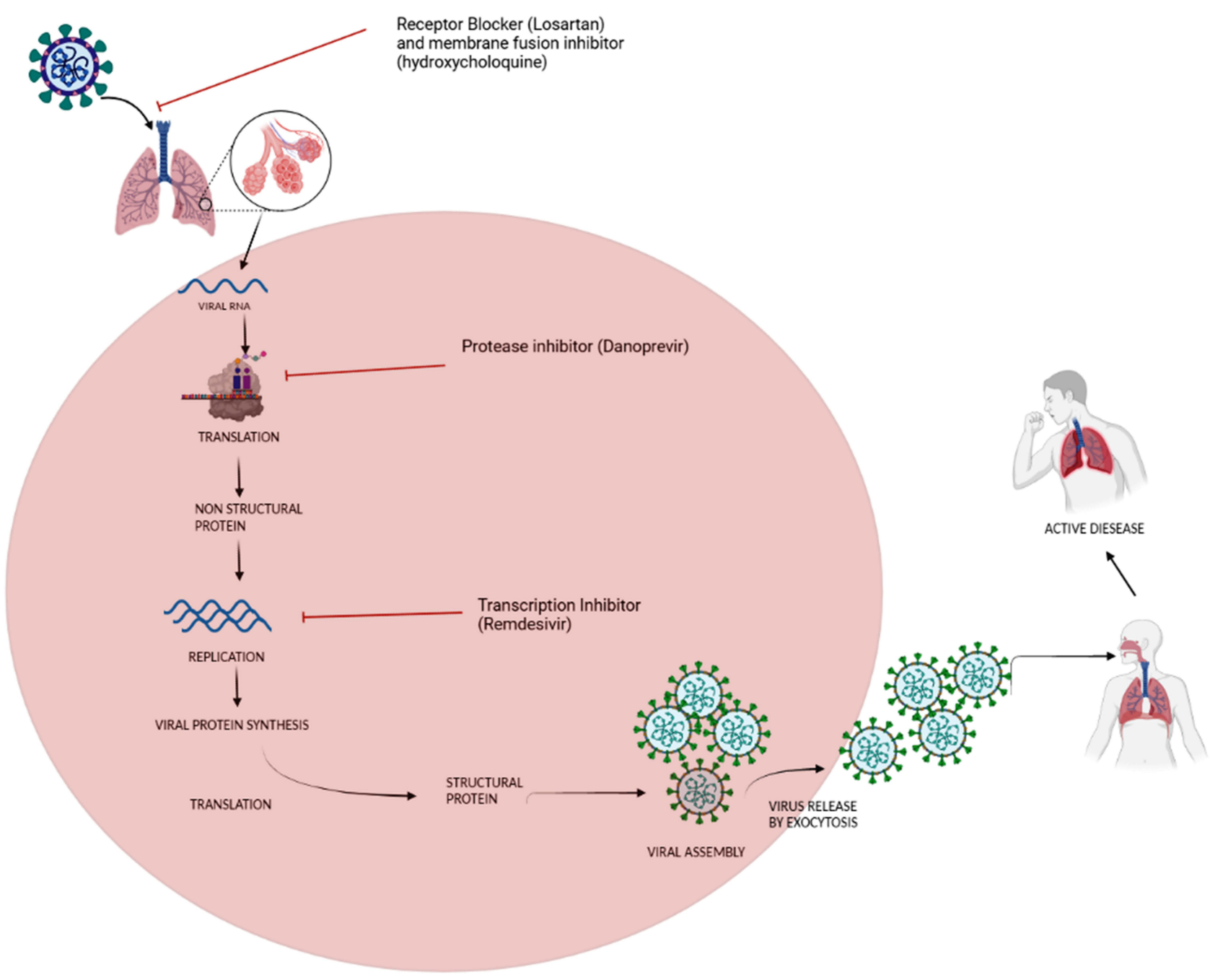

Figure I Mechanism of various drugs/molecules on COVID-19 disease.

rheumatoid arthritis (RA). ${ }^{23}$ CQ and HCQ are reliable anti-malarial drugs approved by FDA, which shows positive response against SARS-CoV-2 infections and hence used for the treatment of COVID-19 patients by clinicians. ${ }^{24-26}$ It inhibits the entry of the virus by either altering the configuration of structure of cell receptors or by compete to bind with cellular receptors. ${ }^{27}$ The glycosylation of ACE-2 cellular receptors can amend by $\mathrm{CQ} /$ HCQ which is needed for entry of SARS-CoV-2. Apart from that $\mathrm{CQ} / \mathrm{HCQ}$ can also prevent the attachment of SARS-CoV-2 to the host cells by decrease the synthesis of sialic acid.

The binding affinity of these drugs is better as compared to the S protein of SARS-CoV-2. Therefore it prevents attachment and entry of virus because of competitive binding of sialic acid and gangliosides present on surface pf target cell. ${ }^{28}$
In addition to the antiviral activity of $\mathrm{CQ} / \mathrm{HCQ}$, they have anti-inflammatory activity that may contribute to its efficacy in treating COVID-19 patients. Through the attenuation of cytokine production, these drugs also have immunomodulatory effects and inhibition of lysosomal and autophagy activity in host cells. ${ }^{24,29}$ In vitro activity of HCQ with lower $\mathrm{EC}_{50}$ for SARS-CoV-2 as compared to $\mathrm{CQ}$ after the growth of 24 hours (HCQ: $\mathrm{EC}_{50}=6.14 \mu \mathrm{M}$ and $\left.\mathrm{CQ}: \mathrm{EC}_{50}=23.90 \mu \mathrm{M}\right){ }^{30}$

A study from China reported which results in improved radiologic findings, enhanced viral clearance, and reduced disease progression by treating successfully with CQ on 100 COVID-19 cases. $^{31}$ When treatment given to 6 patients, then it is observed that as compared to HCQ monotherapy $(8 / 14,57 \%)$ the combination of azithromycin with HCQ $(6 / 6,100 \%)$ results in numerically superior viral clearance. ${ }^{32}$ 
Other than these positive results, this study has many limitations like intolerance of medication, different viral loads between HQC combination and monotherapy and no safety outcomes are reported.

Another study of 30 patients in China shows there was no difference in virologic outcomes to HCQ plus standard of care (supportive care, interferon, and other antivirals). At 7th day virologic clearance was similar with clearance for the HCQ plus standard of care group and standard care group ie $86.7 \%$ vs $93.3 \%$ respectively, $(P>.05) .{ }^{33}$ Currently, for COVID-19 treatment several RCTs of both CQ and HCQ examining their roles. To treat COVID 19 $500 \mathrm{mg}$ dose of CQ orally once or twice daily is advised. ${ }^{8,9}$

However, there is shortage of data regarding the optical dose to ensure efficiency of CQ For HCQ, daily dose of $400 \mathrm{mg}$ taken orally is recommended. ${ }^{34}$

Both the agents are well tolerated by patients with SLE and malaria as demonstrated by their experiences and they can cause rare and serious adverse effect $(>10 \%)$ such as hypoglycemia, neuropsychiatric effects, and retinopathy.

\section{Lopinavir/Ritonavir and Other Antiretrovirals}

Lopinavir/ritonavir is FDA approved for treating HIV and it shows in vitro activity against coronavirus by inhibiting 3-chymotrypsin like protease. ${ }^{35}$ The therapy during early peak viral replication phase (initial 7-10 days) is important because delayed medication with lopinavir/ritonavir had no effective outcomes. ${ }^{36,37}$

Although many RCTs of lopinavir/ritonavir examine their role, limited role for lopinavir/ritonavir in COVID19 treatment is suggested through current data. ${ }^{38}$

Recent RCT shows that approximately $50 \%$ of patients experienced an adverse effect under the lopinavir/ritonavir therapy and $14 \%$ of patients stop therapy due to adverse effects on gastrointestinal region. In several COVID-19 investigational trials, alanine transaminase elevations are exclusion criterion. Hepatotoxicity induced by lopinavir/ ritonavir could limit patients' ability to access these drugs. ${ }^{39}$

The activity of darunavir is demonstrated in vitro cell models against SARS-CoV-2. With these drugs there is no clinical data is available in COVID 19, but in China RCT of darunavir/cobicistat is going on. ${ }^{40,41}$ Ribavirin is a analogue to guanine which inhibits viral RNAdependent RNA polymerase and used as best candidate for treatment of COVID 19.
However, it has limited in vitro activity against SARS$\mathrm{CoV}$ and high doses is required to prevent viral replication (e.g., $1.2 \mathrm{~g}$ to $2.4 \mathrm{~g}$ orally every 8 hours) and combination therapy. For $\mathrm{nCoV}$ treatment no evidence exists for inhaled ribavirin. ${ }^{42}$ Generally ribavirin is used in combination with interferons in the treatment of MERS, no visible effect is shown on clinical outcomes. A lack of clinical data with ribavirin for treatment of COVID 19, means its therapeutic role must be extrapolated from other nCoV data. ${ }^{43,44}$ The high doses used during trials SARS resulted in hematologic toxicity and hemolytic anemia in more than $60 \%$ of patients. Similar safety concerns were seen in MERS trial, with $40 \%$ of patients taking ribavirin with interferon requiring blood transfusions. $75 \%$ of patients experienced transaminase elevations while taking ribavirin for SARS. Ribavirin is a teratogen and prescribed as not to be used pregnancy. ${ }^{45,46}$

\section{Remdesivir}

It is a nucleoside reverse - transcriptase inhibitor that is worthy in clinical trial against COVID-19. It acts as an inhibitor of RNA-dependent RNA polymerase $(\mathrm{RdRp})^{47}$ and in SARS-CoV and MERS-CoV infections its pharmacokinetics and characteristics have been studied. ${ }^{48}$ It inhibits the viral genomic replication and production by disturbed reading due to alteration in the function of viral exonuclease. ${ }^{49}$

Therefore it can suggested for COVID 19 patients to prevent severity of disease progression such patients are taken to phase 3 trials to check the therapeutic efficiency of remdesivir. ${ }^{50}$

\section{Favipiravir}

Favipiravir (T705) is considered as RdRp inhibitor as it is an analog to guanine nucleotide (a derivative of pyrazine carboxamide) ${ }^{51}$ Initially it was used against influenza but because of its large spectrum antiviral properties, it attracted more attention for treatment of COVID $19 .^{52}$

\section{Atazanavir}

An in silico study showed that as compared to lopinavir, atazanavir bound more strongly to the active site of SARSCoV-2 MPro and an in vitro study found that replication of SARS-CoV-2 inhibited by atazanavir. ${ }^{53}$

\section{Other Antivirals}

Oseltamivir is used for treatment of influenza because it acts as a neuraminidase inhibitor. It has no data against 
SARS-CoV-2. Initially in China during the COVID-19 outbreak until the discovery of SARS-CoV-2 as the cause of COVID-19 a large proportion of patients were treated with oseltamivir therapy because outbreak occurred in influenza season.

Once influenza has been excluded this agent has no role in the management of COVID-19. ${ }^{54}$ Umifenovir has a unique mechanism of action targeting the $\mathrm{S}$ protein interaction and inhibiting membrane fusion of the viral envelope. This agent is approved for treatment of influenza in Russia and China and treatment of COVID 19 patients started on the basis of in vitro data which shows its activity against SARS.

A study shows that 67 patients treated with Umifenovir for 9 days had a lower mortality rate and higher discharge rate compared with the patients who were not treated with this medication. This data cannot proof the efficiency of umifenovir, but for evaluating this agent further RCTs are going on in China. ${ }^{55}$

\section{Miscellaneous Agents}

For SARS-CoV- 2 interferon- $\alpha$ and $-\beta$ have been studied, due to their demonstrating activity against MERS by interferon- $\beta$. Some interferons are listed as an alternative for combination therapy by Chinese guidelines. Traditionally other agents are used to demonstrate in vitro activity to inhibit SARS-CoV-2, but not limited to baricitinib, dasatinib, and cyclosporine. However it should be seen whether it provide protection for COVID 19 patients or not. ${ }^{56}$

Nitazoxanide has in vitro antiviral activity against MERS and SARS-CoV-2. It is used traditionally as an antihelminthic agent. More studies are required to check the antiviral activity and immunomodulatory effects of this agent. For treatment option for SARS-CoV-2 nitazoxanide is recommended. ${ }^{57}$ In Japan camostat mesylate is used for treatment of pancreatitis, it prevents cell entry through the host serine protease, TMPRSS2. For future research this mechanism provides an additional drug target. $^{58}$

The ACE2 receptor is used by SARS-CoV-2 for entry into the host cell. This discovery has increased questions about whether ACE inhibitors and/or angiotensin receptor blockers may efficiently treat COVID-19 or either worsen disease. There are some conflicts if these provide protective effect to COVID-19 patients. Further research is pending for recommending therapy for patients already taking one of these agents. ${ }^{59,60}$

\section{The Need for COVID-I 9 Vaccines Multiple Technology Platforms}

One of the main challenges in this pandemic is to develop multiple technology platforms for evaluation of agents/ molecules against SARS-CoV-2 as this virus shows similarity with various other (Figure 1) corona viruses and shares similar binding receptors (ACE2) in humans (host).${ }^{61}$ SARS-CoV-2 has ss-RNA genome of approximately 30 Kbp size and exhibits approximately $89 \%$ nucleotide similarly to SARS-CoV found in Chinese bats. ${ }^{20}$

For SARS-CoV 2 various technologies are being developed such as nucleic acid, replicating viral vector and non-replicating viral vector. New methods based on nucleic acid can facilitate rapid production because they do not need to be fermented. Experiments are conducted to ensure vaccination of larger population without any reduction in efficacy but also with improved immune response along with low dosages. ${ }^{62,63}$

\section{Stratagems for the COVID-I 9 Vaccine}

As of January 2021, more than 200 vaccine candidates for COVID-19 are being tested. Among these almost 52 vaccines are approved for human trials and many other vaccines are in phases I/II and will soon enter phase III trials. Certain national regulatory authorities have nine authorized COVID-19 vaccines.

\section{Whole Virus Vaccines}

It represents a classic strategy for viral vaccinations. Finally, a "codon deoptimization" technology to attenuate the viruses is employed by Codagenix ${ }^{64}$ and is testing to develop vaccine against SARS-CoV-2, CodaVax-COVID. The inherent immunogenicity and ability to stimulate tolllike receptors (TLRs) is a major advantage of whole virus vaccines. This is especially an issue for coronavirus vaccines, given the findings of increased infectivity following immunization with live or killed whole virus SARS coronavirus vaccines. ${ }^{65}$

\section{Subunit Vaccines}

Subunit vaccines depend on producing immune response against $\mathrm{S}$ protein to inhibit its binding with host ACE2 receptor. ${ }^{65}$ Immunogenic virus-like nanoparticles produced by Novavax are based on recombinant expression of the S-protein ${ }^{66}$ while subunit vaccine consisted of a trimerized SARS-CoV-2 S-protein is developed by Clover 
Biopharmaceuticals by using their patented Trimer-Tag ${ }^{\circledR}$ technology. ${ }^{67}$

\section{Nucleic Acid Vaccines}

For development of COVID-19 vaccines several major biotech industries have advanced nucleic acid vaccine platforms. Some modifications and formulation have improved nucleic acid performance in humans. This approach may lead to the first licensed nucleic acid based vaccine for humans.

\section{Challenges in COVID- 19 Vaccine Development}

Developing vaccine against the SARS-CoV-2 can cause distinct challenges. Various proteins of SARS-CoV-2 are used for developing proteins like $\mathrm{S}$ protein, $\mathrm{N}$ protein, $\mathrm{M}$ protein is the initial challenge. Developing a vaccine is a long process, starting from product development to the completion of phase III and clinical trials before marketing which takes several years.

\section{Bharat Biotech Set to Develop and Test Vaccine for COVID-19}

Vaccine against COVID-19, known as "CoroFlu" is under process and its development and testing is done by Bharat Biotech in collaboration with international virologists and vaccine makers. One-drop COVID-19 nasal vaccine named CoroFlu, it is well tolerated in human trials during phase I and phase II. On the backbone of FluGen's flu vaccine, CoroFlu has built a candidate known as M2SR. M2SR induces an immune response against the flu; it is a self-limiting version of the influenza virus. To induce immunity against the coronavirus in new virus, Kawaoka's lab is trying to insert the gene sequences from SARS-CoV -2 into M2SR. ${ }^{68}$

\section{Zydus Cadila Launches a Fast-Tracked Program to Develop SARS-CoV-2 Vaccine}

To develop a vaccine for SARS-CoV-2, Zydus Cadila, an innovation-driven global pharmaceutical company, initiated a research program along with multiple teams. By reverse genetics the recombinant measles virus (rMV) is produced. It would express codon optimised proteins of the SARS-CoV-2 and provide long-term neutralising antibodies for protection from infection. The plasmid DNA vaccine, also has wide ranging capabilities in developing and manufacturing different vaccines for unmet needs. This is under supervision of the group's Vaccine Technology Centre in India. ${ }^{69}$

\section{Up for COVID-I9 Vaccine Research}

To develop a lead vaccine candidate for SARS-CoV-2 the Vaccine manufacturer Indian Immunologicals Ltd (IIL) has a research collaboration agreement with Australia's Griffith University. As part of the cross-continental collaboration, using the latest codon de-optimisation technology Live Attenuated SARS-CoV-2 vaccine could be developed by scientists from IIL and the Griffith University. with a single dose administration this vaccine is expected to provide long protection with an anticipated safety profile for active immunization. $^{70}$

\section{Indian Institute Captivating Step Ladders}

\section{Serum Institute of India (SII)}

Now the SII (Serum Institute of india) is preparing its mass production against the coronavirus, mixing out doses of the "Covishield" candidate vaccine which is being developed by the University of Oxford and the international biopharma company AstraZeneca. In India stage III clinical trials of Covishield are continuing. In the US, Brazil and South Africa the candidate vaccine is also being tested in various stages. Two million doses of the vaccine candidate has already produced over for use in testing by the SII. Recently SII announced a deal with Codagenix, US-based Biotech Company to help develop a vaccine candidate and it is expected that its trials starts by the end of 2020. Nasal COVID-19 vaccine candidate developed by Codagenix Inc. Dubbed the DX-005, manufacturing by SII has started.

After completing preclinical animal studies the coronavirus vaccine entered phase I clinical trials in the United Kingdom by the end of 2020. Bharat Biotech, a private firm collaborated with Indian Council of Medical Research (ICMR) is developing Covaxin. "Covaxin has shown good efficacy" is said by task force scientist Dr. Rajni Kant ICMR-COVID-19. Bharat Biotech is approved by The Drugs Controller General of India (DCGI) to perform Phase III clinical trials of Covaxin with certain conditions.

\section{Rejected Vaccines and Vaccination Hesitancy}

Russia's president Vladimir Putin endorsed approval of "SPUTNIK V" (COVID-19 vaccine) that has not passed 
rigorous medical tests and could have numerous consequences. The effectiveness of the vaccine in response to providing active acquired immunity against COVID-19 and its possible adverse effects remain unknown. Therefore, the fear of vaccination in this particular case may be justified. However, endorsement of a potentially harmful vaccine will inevitably fuel public fears of other existing and future, properly developed, controlled and safe vaccines. Current level of public acceptability of immunization is already worrying, putting at serious risk the effectiveness of any future anti-SARS-CoV-2 vaccination programs, as it has been pointed out by Cornwall 2 and the French COCONEL Group 3. Independently from each other these groups provide evidence that it is a transatlantic phenomenon. Regardless of the suggested correlations between vaccination hesitancy and specific socioeconomic factors, it is clear that anti-vaccination movements are increasingly influential. ${ }^{71}$ Moreover, the problem is internationally valid, and the rise in the number of adults openly hesitant about routine childhood vaccination in many Western countries justifies the concern about public participation once the COVID-19 vaccine is available. $^{72}$

In terms of collective immunity, vaccination effectiveness is based on its mass implementation; this may seriously undermine the efforts to protect societies against COVID-19 in the near future. High levels of COVID-19 vaccine hesitancy are reported even from countries severely affected by the pandemic. Only $49 \%$ of American respondents plan to vaccinate when the vaccine becomes available. ${ }^{73}$

Polish research confirms the strong COVID-19 vaccination hesitancy and its international character which is not directly related to the level of confidence in vaccination safety in general. Results of this Polish study show that $28 \%$ of adults would not vaccinate against SARS-CoV -2 if the vaccine became available. Alarmingly, a majority $(51 \%)$ of the reluctant respondents indicated that their minds would not be changed if given information regarding vaccine safety or efficacy, or if threatened with heavy fines. Significantly fewer respondents (37\%) supported COVID-19 vaccinations specifically than supported childhood vaccinations in Poland in general (78\% in 2018). ${ }^{74}$ The vaccine hesitancy for the anticipated COVID-19 vaccine varied from very low (2-6\% China) to very high (43\%, Czechia, and 44\%, Turkey). Surprisingly, the level of unwillingness to vaccinate against COVID-19 is in most countries much higher than regular vaccination reluctance, which varies between 3\% (Egypt) and 55\% (Russia). Such high levels of vaccination hesitancy may be detrimental to public health. According to current estimates, the benefits of herd immunity are achievable if $67 \%$ of the population is vaccinated. ${ }^{75,76}$

The most effective vaccination programs in the past effectively eradicated certain deadly diseases, such as smallpox which was achieved by combining the mandatory preventive vaccination programs with coordinated education efforts. ${ }^{77}$ Coronaviruses mortality rate is the highest among elders and people with comorbidities or conditions that affect their immune system. Some occupations have been identified as being the riskiest in terms of contracting COVID-19 such as health-care workers (dental hygienists, family practitioners, and nurses), transportation personnel (flying attendants, and school bus drivers), kindergarten, school teachers, fire fighters and restaurant personnel. ${ }^{78}$ Highest risk of death and highest risk of contraction should constitute the main criteria for mandatory vaccination. Mandatory vaccination will definitely trigger massive opposition especially bearing in mind the massive protests against social distancing measures and face masks. Focusing at the beginning only on some groups with transparent justification may help weaken the opposition to it. ${ }^{79}$

The high share of the population unwilling to vaccinate along with the number of people who are unable to receive the COVID-19 vaccine due to certain medical reasons suggests herd immunity may be out of reach. Information about the high death tolls and hospital overflows from the COVID-19 pandemic has recently flooded onto online media, but has apparently not convinced much of the world's population to plan to be vaccinated. If the disturbing images being streamed live on social media cannot convince a fair share of the population to protect themselves from lethal risk, then educational or social campaigns may be limited in their effect. Educational efforts would be further undermined by the lack of trust in public authority figures, which fuels conspiracy theories and validates medical fake news. In this focused review we have discussed the challenges and opportunities faced during the management of COVID-19 in India.

\section{Challenges Faced by Health Care Workers (HCWs)}

Health-care systems across developed and developing nations are under tremendous pressure. The majority of 
this responsibility is being shouldered by frontline healthcare workers to limit the spread of the novel coronavirus. They put their lives on the line in order to do so. Here we highlight some challenges faced by frontline $\mathrm{HCW}$ and propose certain recommendations to reduce the burden.

The exposure to the virus causes severe illness and mortality to a significant extent and also leads to physical and psychological exhaustion. This pandemic leads to health departments calling retired and experienced medical staff and clinical scientist back to work. Deficient supplies of personal protective equipment (PPEs) and other vital necessities is reported in various news channels all over the world. Majorly WHCs are affected and they are working in the emergency, they need PPEs and other vital necessities most.

In this pandemic, battling endless hours, staff shortages and deficient supplies, most are isolated from their families, affecting them physically, mentally, and emotionally, which will increase the morbidity and ill health. ${ }^{80}$ These mental health problems will not only affect decision making ability, judgement and attention of HCWs, but also affect the understanding the disease and have a longlasting impact on their overall well-being. ${ }^{80}$

A few recommendations are proposed which are listed from all the information received around this issue.

\section{Health Check-Up of Frontline Health Care Staff as a Priority}

Health-care staff/HCWs are also the most important resource as hospitals, equipments and PPEs in this pandemic situation. Post Traumatic Stress Disorder is reported in many health-care workers who have no time to protect themselves as well as their families. If any staff gets infected then they should be quarantined themselves, which leads to a shortage of staff and then healthy workers are stretched further for endless duties with lack of sleep and anxiety. For frontline health workers testing kits must be prioritized, as well as for weak communities (senior citizens) more susceptible to the virus and those who have many pre-existing diseases. ${ }^{81,82}$

\section{Providing PPEs to All Frontline Workers}

Health-care workers face a high risk of getting infected as they take care of patients who are already infected. Protective clothing, sufficient hand sanitizers, washing paraphernalia and head covers are essential commodities which have to be provided to them in sufficient amount. Along with providing PPEs in adequate amount, its disposal methodology is also an important step across all the clinical areas since it can be one of the reasons of spreading infection. ${ }^{31}$

\section{Self-Isolation, Social Isolation and Quarantine}

These are key phrases which provide the adequate time for the systems to gather resources and capacity to help in breaking the chain of transmission. The virus infects exponentially which is very clear and many will contract it very soon. State should provide premises to serve as isolation ward and quarantine spaces. All hospitals should use their full area to create control committees to monitor activities to ensure protocols are implemented for effective control. The loop has to be complete, involving community systems, governments and primary health-care workers are key, since not everyone will report to hospitals, if community transmission will be rampant.

\section{Utilisation of Training, Knowledge and Protocols to Follow}

The comfort and willingness in working for a health system which has an effective plan, magnifies many times in a pandemic. Protocols in local languages for better understanding and awareness material based on science research have been useful. Offering free transport service between work and home, childcare support and meal vouchers can reduce domestic stress and allow single-minded effort towards the health service. ${ }^{83}$

\section{General Achievements Arrived During Fight Against COVID 19 Pandemic}

Apart from the various negative effect imposed by the pandemic, positive vibes of it cannot be neglected. The pandemic situation significantly improves air quality in different cities across the country, reduces GHGs emission, lessens water pollution and noise, and reduces the pressure on the tourist destinations, which may assist with the restoration of the ecological systems. ${ }^{84}$ These changes may be short term but are important for maintenance of environmental balance. Apart from this, various successful models like that of Dharavi and Kerala model were implemented which restricted the cases to a minimum through observing the spread in the localities, studying the prototype of spread, and strict use of methods to control the disease in Kerala. Dharavi restricted 
the coronavirus cases with a strategy of attack not defence and elucidated triumphant results in 2 months. ${ }^{85}$

\section{COVID I 9 Vaccine Update}

There are more than 56 COVID-19 candidate vaccines in clinical evaluation of which 13 are in phase III trials and another 166 candidate vaccines are in preclinical evaluation (Table 1). All top candidate vaccines will be delivered through intra-muscular injection and are designed for a two-dose schedule. ${ }^{86}$ More recently our group has suggested the combinatorial use of childhood vaccines (BCG, MMR and OPV) along with the COVID-19 dedicated vaccines could be a potential strategy to control the COVID-19 pandemic worldwide. ${ }^{87}$

\section{Latest Update on 2nd Wave of COVID-I 9}

Strain B.1.1.7 was first detected in the United States in December 2020 followed by B.1.351, in South Africa P.1, in Brazil and Japan, B.1.427 and B.1.429. These two variants were first identified in California in February 2021. COVID-19 variant from India is B.1.617; one of the lineages is B.1.617.2, which has been detected most frequently in the US and the U.K. ${ }^{88}$ Recently the "black fungus" is now maiming COVID-19 patients in India. Mucormycosis is an invasive infection caused by a class of molds called mucormycetes. It has an overall mortality rate of $50 \%$, and may be being triggered by the use of unhygienic oxygen cylinders and steroids, a life-saving treatment for severe and critically ill COVID-19 patients. ${ }^{89}$

\section{Conclusion}

In this review, we have been discussed the stories related to prevention strategies, chemotherapeutics and vaccines strategies to manage COVID-19. Apart from that we have discussed the challenges faced by HCWs and their prevention. Combating COVID-19 is still a challenge also due to the poorly-based counsel for using an experimental amalgamation of antimalarials and antimicrobials as treatment; the use of steroids; and antihypertensive drugs during the course of the disease. Interruption of the transmission of SARS-CoV-2 through engineered vaccines is top in the priority followed by the intense research to find out the potential treatment to control this viral infection.

Table I Prospective Therapeutic Representative Against COVID-19 Disease

\begin{tabular}{|c|c|c|c|}
\hline $\begin{array}{l}\text { Candidate Vaccines in Phase III Clinical } \\
\text { Evaluation }\end{array}$ & Antivirals & Antibiotics & $\begin{array}{l}\text { Laboratory Anomalies } \\
\text { During COVID } 19 \text { Stages }\end{array}$ \\
\hline Sinovac & $\begin{array}{c}\text { Lopinavir- } \\
\text { Ritonavir (Lpv- } \\
\text { Rtv) }\end{array}$ & Azithromycin & Crp \\
\hline Astra Zeneca & Remdesivir (Rdv) & Teicoplanin & Decreased Albumin \\
\hline Wuhan Institute Of Biological Products/Sinopharm & Favipiravir (Fpv) & Doxycycline & Increased Lactate Dehydrogenase \\
\hline Bharat Biotech & Arbidol (Arb) & Immune Modulators & Alanine Aminotransferase \\
\hline Cansino Biological Inc./Beijing Institute Of Biotechnology & Ribavirin & Baricitinib & Aspartate Aminotransferase \\
\hline Gamaleya Research Institute & Chloroquine & Corticosteroids (Css) In & Bilirubin \\
\hline Janssen Pharmaceutical Companies & $\begin{array}{l}\text { Hydroxy } \\
\text { Chloroquine }\end{array}$ & $\begin{array}{c}\text { Cytokine-Targeted } \\
\text { Monoclonal Antibodies }\end{array}$ & Creatinine \\
\hline Novavax & Saquinavir & Jak Inhibitors & Cardiac Troponin \\
\hline $\begin{array}{l}\text { Anhui Zhifei Longcom Biopharma/ Institute Of } \\
\text { Microbiology, Chinese Academy Of Sciences }\end{array}$ & Nelfinavir & $\begin{array}{l}\text { Biologically Active } \\
\text { Polysaccharides }\end{array}$ & D-Dimer \\
\hline Moderna/Niaid & Carfilzomib & Phytotherapeuticals & Procalcitonin, \\
\hline Biontech/Fosun Pharma/Pfizer & Zanamivir & $\begin{array}{c}\text { Synthetic } \\
\text { Immunomodulators }\end{array}$ & \\
\hline Medicago Inc. & Ivermectin & & \\
\hline
\end{tabular}




\section{Author Contributions}

All authors contributed to data analysis, drafting or revising the article, have agreed on the journal to which the article will be submitted, gave final approval of the version to be published, and agree to be accountable for all aspects of the work.

\section{Funding}

There is no funding to report.

\section{Disclosure}

Divakar Sharma and Dileep Tiwari were associated with Hericure Healthcare Pvt Ltd. Currently, Divakar Sharma is working in Maulana Azad Medical College at the time of this review. The authors reported no other potential conflicts of interest for this work.

\section{References}

1. Hoffmann M, Kleine-Weber H, Krüger N, et al. SARS-CoV-2 Cell Entry Depends on ACE2 and TMPRSS2 and Is Blocked by a Clinically Proven Protease Inhibitor. Cell. 2020;181(2):271-280. doi:10.1016/j.cell.2020.02.052

2. Fischer F, Raiber L, Boscher C, et al. COVID-19 and the elderly: who cares? Front Public Health. 2020;8:151. doi:10.3389/ fpubh.2020.00151

3. Vahia IV, Blazer DG, Smith GS, et al. COVID-19, mental health and aging: a need for new knowledge to bridge science and service. $\mathrm{Am}$ J Geriatr Psychiatry. 2020;28(7):695. doi:10.1016/j.jagp.2020.03.007

4. COVID-19. Tracker India; 2020. Available from: https://www. COVID19india.org/. Accessed April 15, 2020.

5. Census-India. 2011. Available from: https://censusindia.gov.in/2011Common/CensusData2011.html. Accessed April 15, 2020.

6. Mishra VK. India's projected aged population (65?), projected life expectancy at birth and insecurities faced by aged population. Ageing International. 2020;45:72-84.

7. De Witt Huberts J, Greenland K, Schmidt W-P, et al. Exploring the potential of antimicrobial hand hygiene products in reducing the infectious burden in low-income countries: an integrative review. $\mathrm{Am}$ J Infect Control. 2016;44(7):764-771. doi:10.1016/j.ajic.2016.01.045

8. U.S. Food and Drug Administration. Temporary policy for preparation of certain alcoholbased hand sanitizer products during the public health emergency (COVID-19). Guidance for Industry; March, 2020. Available from: https://www.fda.gov/media/136289/download. Accessed July 21, 2021.

9. Edwards J, Patel G, Wareham DW. Low concentrations of commercial alcohol hand rubs facilitate growth of and secretion of extracellular proteins by multidrug-resistant strains of Acinetobacter baumannii. J Med Microbiol. 2007;56(12):1595-1599. doi:10.1099/ jmm.0.47442-0

10. healthcare-in-europe.com [Internet]. Will resistant bacteria be the end of alcohol hand sanitizers? 2018. Available from: https://healthcare-in -europe.com/en/news/will-resistant-bacteria-be-the-end-of-alcoholhand-sanitizers.html\#. Accessed July 21, 2021.

11. Lan J, Song Z, Miao X, et al. Skin damage among health care workers managing coronavirus disease-2019. J Am Acad Dermatol. 2020;82(5):1215-1216. doi:10.1016/j.jaad.2020.03.014

12. The Government of India issues simple guidelines, for controlling spread of COVID-19 in densely populated areas. Available from: https://pib.gov.in/PressReleseDetailm.aspx?PRID=1614064. Accessed July 21, 2021.
13. TIFAC explores best methods to revive Indian economy post COVID19. Available from: https://dst.gov.in/tifac-explores-best-methodsrevive-indian-economy-post-COVID-19. Accessed July 21, 2021.

14. TDB approves support for indigenous company for ramping up production of COVID-19 diagnostic kits. Available from: https:// dst.gov.in/tdb-approves-support-indigenous-company-rampingproduction-COVID-19-diagnostic-kits. Accessed July 21, 2021.

15. NBRI scientists develop herbal hand-sanitiser. Available from: https://vigyanprasar.gov.in/isw/NBRI-scientists-develop-herbal-handsanitiser.html. Accessed July 21, 2021.

16. Indian researchers to go for clinical trial of sepsis drug against novel coronavirus. Available from: https://vigyanprasar.gov.in/ wp-content/uploads/Indian-researchers-to-go-for-clinical-trial-ofsepsis-drug-against-novel-coronavirus-21apr20.pdf. Accessed July 21, 2021.

17. Advisory_on_Cepheid_Xpert_Xpress_SARS_CoV2_testing. AvailabAdvisory_on_Cepheid_Xpert_Xpress_SARS_CoV2_testing. Available from: https://icmr.nic.in/sites/default/files/upload_documents/ Advisory_on_Cepheid_Xpert_Xpress_SARS_CoV2_testing.pdf. Accessed July 21, 2021.

18. AMU alumnus develops COVID-19 testing kit, approved by ICMR. Available from: https://www.amu.ac.in/about3.jsp?did=2495. Accessed July 21, 2021.

19. Bione launches rapid COVID-19 at-home screening test kit after ICMR approval. Available from: https://zeenews.india.com/india/ bione-launches-rapid-COVID-19-at-home-screening-test-kit-aftericmr-approval-2273752.html. Accessed July 21, 2021.

20. Wu F, Zhao S, Yu B, et al. Complete genome characterisation of a novel coronavirus associated with severe human respiratory disease in Wuhan, China. bioRxiv. 2020;2020:919183. doi:10.1101/ 2020.01.24.919183

21. Chen Y, Liu Q, Guo D. Emerging coronaviruses: genome structure, replication, and pathogenesis. J Med Virol. 2020;92(4):418-423. doi: $10.1002 / \mathrm{jmv} .25681$

22. Fung TS, Liu DX. Coronavirus infection, ER stress, apoptosis and innate immunity. Front Microbiol. 2014;5:296. doi:10.3389/ fmicb.2014.00296

23. Savarino A, Boelaert JR, Cassone A, et al. Effects of chloroquine on viral infections: an old drug against today's diseases. Lancet Infect Dis. 2003;3(11):722-727. doi:10.1016/S1473-3099(03) 00806-5

24. Devaux CA, Rolain J-M, Colson P, et al. New insights on the antiviral effects of chloroquine against coronavirus: what to expect for COVID-19? Int $J$ Antimicrob Agents. 2020;55(5):105938. doi:10.1016/j.ijantimicag.2020.105938

25. Li R, Yin K, Zhang K, et al. Application prospects of virtual autopsy in forensic pathological investigations on covid-19. Fa yi xue za zhi. 2020;36(2):149-156. Chinese.

26. Gao J, Hu S. Update on use of chloroquine/hydroxychloroquine to treat coronavirus disease 2019 (COVID-19). BioSci Trends. 2020;14 (2):156-158. doi: $10.5582 /$ bst.2020.03072

27. Quiros Roldan E, Biasiotto G, Magro P, et al. The possible mechanisms of action of 4-aminoquinolines (chloroquine/hydroxychloroquine) against Sars-Cov-2 infection (COVID-19): a role for iron homeostasis? Pharmacol Res. 2020;158:104904. doi:10.1016/j. phrs.2020.104904

28. Fantini J, Di Scala C, Chahinian H, et al. Structural and molecular modelling studies reveal a new mechanism of action of chloroquine and hydroxychloroquine against SARS-CoV-2 infection. Int $J$ Antimicrob Agents. 2020;55(5):105960. doi:10.1016/j. ijantimicag.2020.105960

29. Zhou D, Dai SM, Tong Q. COVID-19: a recommendation to examine the effect of hydroxychloroquine in preventing infection and progression. $J$ Antimicrob Chemother. 2020:75:1667-1670. doi:10.1093/jac/dkaa114 
30. Yao X, Ye F, Zhang M, et al. In vitro antiviral activity and projection of optimized dosing design of hydroxychloroquine for the treatment of severe acute respiratory syndrome coronavirus 2 (SARS-CoV-2). Clin Infect Dis. 2020;71(15):732-739. doi: $10.1093 / \mathrm{cid} / \mathrm{ciaa} 237$

31. Jain U. Risk of COVID-19 due to shortage of personal protective equipment. Cureus. 2020;12:6 e8837. doi:10.7759/ cureus. 8837

32. Gautret P, Lagier J-C, Parola P, et al. Hydroxychloroquine and azithromycin as a treatment of COVID-19: results of an open-label non-randomized clinical trial. Int J Antimicrob Agents. 2020;56 (1):105949. doi:10.1016/j.ijantimicag.2020.105949

33. Chen J, Liu D, Liu L, et al. A pilot study of hydroxychloroquine in treatment of patients with common coronavirus disease-19 (COVID-19). J Zhejiang Univ. 2020. doi:10.3785/j.issn.10089292.2020.03.03

34. McMichael TM, Currie DW, Clark S, et al. Public Health-Seattle and King County, evergreen health, and CDC COVID-19 Investigation Team. Epidemiology of COVID-19 in a long-term care facility in King County, Washington. N Engl J Med. 2020;382(21):2005-2011. doi:10.1056/NEJMoa2005412

35. Chu CM, Cheng VC, Hung IF, et al; HKU/UCH SARS Study Group. Role of lopinavir/ritonavir in the treatment of SARS: initial virological and clinical findings. Thorax. 2004;59(3):252-256. doi:10.1136/ thorax.2003.012658

36. de Wilde AH, Jochmans D, Posthuma CC, et al. Screening of an FDA-approved compound library identifies four small-molecule inhibitors of Middle East respiratory syndrome coronavirus replication in cell culture. Antimicrob Agents Chemother. 2014;58(8):4875-4884 doi:10.1128/AAC.03011-14

37. Cao B, Wang Y, Wen D, et al. A trial of lopinavir-ritonavir in adults hospitalized with severe COVID-19. N Engl J Med. 2020;382 (19):1787-1799. doi:10.1056/NEJMoa2001282

38. Wang M, Cao R, Zhang L, et al. Remdesivir and chloroquine effectively inhibit the recently emerged novel coronavirus (2019-nCoV) in vitro. Cell Res. 2020;30(3):269-271. doi:10.1038/ s41422-020-0282-0

39. Rossignol J-F. Nitazoxanide, a new drug candidate for the treatment of Middle East respiratory syndrome coronavirus. J Infect Public Health. 2016;9(3):227-230. doi:10.1016/j.jiph.2016.04.001

40. Gurwitz D. Angiotensin receptor blockers as tentative SARS-CoV-2 therapeutics. Drug Dev Res. 2020;81(5):537-540. doi:10.1002/ ddr. 21656

41. Totura AL, Bavari S. Broad-spectrum coronavirus antiviral drug discovery. Expert Opin Drug Discov. 2019;14(4):397-412. doi:10.1080/17460441.2019.1581171

42. Li G, De Clercq E. Therapeutic options for the 2019 novel coronavirus (2019-nCoV). Nat Rev Drug Discov. 2020;19(3):149-150. doi:10.1038/d41573-020-00016-0

43. Stockman LJ, Bellamy R, Garner P, Low D. SARS: systematic review of treatment effects. PLoS Med. 2006;3(9):e343. doi:10.1371/journal.pmed.0030343

44. Morra ME, Van Thanh L, Kamel MG, et al. Clinical outcomes of current medical approaches for Middle East respiratory syndrome: a systematic review and meta-analysis. Rev Med Virol. 2018;28(3): e1977. doi:10.1002/rmv.1977

45. National Health Commission and State Administration of Traditional Chinese Medicine. Diagnosis and treatment protocol for novel coronavirus pneumonia. Accessed March 18, 2020.

46. Kadam RU, Wilson IA. Structural basis of influenza virus fusion inhibition by the antiviral drug arbidol. Proc Natl Acad Sci U S A. 2017;114(2):206-214. doi:10.1073/pnas.1617020114

47. Gordon CJ, Tchesnokov EP, Feng JY, et al. The antiviral compound remdesivir potently inhibits RNA-dependent RNA polymerase from Middle East respiratory syndrome coronavirus. $J$ Biol Chem. 2020:013056. doi:10.1074/jbc.AC120.013056
48. Agostini ML, Andres EL, Sims AC, et al. Coronavirus susceptibility to the antiviral remdesivir (GS-5734) is mediated by the viral polymerase and the proofreading exoribonuclease. mBio. 2018;9(2): e00221-e00318. doi:10.1128/mBio.00221-18

49. Sharma D, Kunamneni A. Recent progress in the repurposing of drugs/molecules for the management of COVID-19. Expert Rev Anti Infect Ther. 2021;19(7):889-897. doi:10.1080/ 14787210.2021.1860020

50. Amirian ES, Levy JK. Current knowledge about the antivirals remdesivir (GS-5734) and GS-441524 as therapeutic options for coronaviruses. One Health. 2020;9:100128. doi:10.1016/j. onehlt.2020.100128

51. Shiraki K, Daikoku T. Favipiravir, an anti-influenza drug against life-threateningRNA virus infections. PharmacolTher. 2020:209; 107512.

52. Calling all coronavirus researchers: keep sharing, stay open. Nature. 2020;578(7793):7. doi:10.1038/d41586-020-00307-x

53. Fintelman-Rodrigues N, Sacramento CQ, Lima CR, et al. Atazanavir inhibits SARS-CoV-2 replication and pro-inflammatory cytokine production. bioRxiv. 2020. doi:10.1101/2020.04.04.020925

54. Khamitov RA, Loginova S, Shchukina VN, et al. Antiviral activity of arbidol and its derivatives against the pathogen of severe acute respiratory syndrome in the cell cultures. Vopr Virusol. 2008;53 (4):9-13. [in Russian]

55. Wang Z, Yang B, Li Q, et al. Clinical features of 69 cases with coronavirus disease 2019 in Wuhan, China. Clin Infect Dis. 2020;71 (15):769-777.

56. de Wilde AH, Zevenhoven-Dobbe JC, van der Meer Y, et al. Cyclosporin A inhibits the replication of diverse coronaviruses. $J$ Gen Virol. 2011;92(11):2542-2548. doi:10.1099/vir.0.034983-0

57. Foolad F, Aitken SL, Shigle TL, et al. Oral versus aerosolized ribavirin for the treatment of respiratory syncytial virus infections in hematopoietic cell transplant recipients. Clin Infect Dis. 2019;68 (10):1641-1649. doi:10.1093/cid/ciy760

58. Arabi YM, Shalhoub S, Mandourah Y, et al. Ribavirin and interferon therapy for critically ill patients with Middle East respiratory syndrome: a multicenter observational study. Clin Infect Dis. 2020;70 (9):1837-1844.

59. ClinicalTrials.gov. Available from: https://clinicaltrials.gov/. Accessed March 18, 2020.

60. Sharma D, Sharma J, Singh A, Anand V. Exploring the mystery of Angiotensin-Converting Enzyme II (ACE2) in the battle against SARS-CoV-2. J Renin Angiotensin Aldosterone Syst. 2021;2021:1-5. doi:10.1155/2021/9939929

61. Resources for Researchers. Available from: https://www.niaid.nih. gov/research/resources?search=COVID\%20VACCINE. Accessed July 21, 2021.

62. Lurie N, Saville M, Hatchett R, et al. Developing COVID-19 vaccines at pandemic speed. N Engl J Med. 2020;382(21):1969-1973.

63. Le TT, Cramer JP, Chen R, et al. Evolution of the COVID-19 vaccine development landscape. Nat Rev Drug Dis. 2020;19(10):667-668. doi:10.1038/d41573-020-00151-8

64. Shieber J. Codagenix raises $\$ 20$ million for a new flu vaccine and other therapies. Tech Crunch. Available from: https://techcrunch.com/ 2020/01/13/codagenix-raises-20-million-for-a-new-flu-vaccine-andothertherapies/. Accessed February 28, 2020.

65. Jiang S, Bottazzi ME, Du L, et al. Roadmap to developing a recombinant coronavirus $\mathrm{S}$ protein receptor-binding domain vaccine for severe acute respiratory syndrome. Expert Rev Vaccines. 2012;11(12):1405-1413. doi:10.1586/erv.12.126

66. Coleman CM, Liu YV, Mu H, et al. Purified coronavirus spike protein nanoparticles induce coronavirus neutralizing antibodies in mice. Vaccine. 2014;32(26):3169-3174. doi:10.1016/j.vaccine.2014.04.016

67. Clover Biopharmaceuticals. Clover Initiates Development of Recombinant Subunit-Trimer Vaccine for Wuhan Coronavirus (2019- nCoV); 2020. 
68. Bharat Biotech [homepage]. Available from: https://www.bharatbio tech.com/. Accessed July 21, 2021.

69. Available from: https://zyduscadila.com/public/pdf/pressrelease/ Zydus_Cadila_launches_a_fast_tracked_programme_to_develop_vac cine_for_the_novel_coronavirus_2019-nCoVCOVID-19).pdf. Accessed July 21, 2021.

70. IIL in the News; 2020. Available from: https://www.indimmune.com/ mediia/iil-news. Accessed July 21, 2021.

71. Schaffer DeRoo S, Pudalov NJ, Fu LY. Planning for a COVID-19 vaccination program. JAMA. 2020;323(24):2458. doi:10.1001/jama.2020.8711

72. Ball P. Anti-vaccine movement could undermine efforts to end coronavirus pandemic, researchers warn. Nature. 2020;581(7808):251. doi:10.1038/d41586-020-01423-4

73. The Associated Press-NORC Center for Public Affairs Research. Expectations for a COVID-19 vaccine. NORC at the University of Chicago. 2020. Available from: http://www.apnorc.org/projects/Pages/ Expectations-for-a-COVID-19-Vaccine.aspx. Accessed 31, 2020.

74. Feleszko W, Lewulis P, Czarnecki A, Waszkiewicz P. Flattening the curve of COVID-19 vaccine rejection-a global overview. SSRN Electron J. 2020. doi:10.2139/ssrn.3631972

75. Randolph HE, Barreiro LB. Herd immunity: understanding COVID-19. Immunity. 2020;52(5):737-741. doi:10.1016/j. immuni.2020.04.012

76. The Lancet Infectious D. Political casualties of the COVID-19 pandemic. Lancet Infect Dis. 2020;20(7):755

77. Omer SB, Salmon DA, Orenstein WA, et al. Vaccine refusal, mandatory immunization, and the risks of vaccine-preventable diseases. $N$ Engl J Med. 2009;360(19):1981-1988. doi:10.1056/NEJMsa0806477

78. $\mathrm{Lu} \mathrm{M}$. These are the occupations with the highest COVID-19 risk. World Economic Forum; April 20, 2020 Available from: https:// www.weforum.org/agenda/2020/04/occupations-highest-COVID19risk/. Accessed July 21, 2021.

79. Sanders M, Monogue ML, Jodlowski TZ, et al. Pharmacologic treatments for Coronavirus Disease (COVID-19) a review. JAMA. 2020;323(18):1824-1836.

80. Jain A, Bodicherla KP, Raza Q, Sahu KK. Impact on mental health by "living in isolation and quarantine" during COVID-19 pandemic. J Family Med Prim Care. 2020;9(10):5415-5418. doi:10.4103/ jfmpc.jfmpc_1572_20
81. Sur J, Sharma J, Sharma D. Diabetes might augment the severity of COVID-19: a current prospects. Front Cardiovasc Med. 2021;7:613255. PMID: 33409238; PMCID: PMC7773080. doi:10.3389/fcvm.2020.613255

82. Sharma J, Sharma D. Prevention and management of SARS-CoV-2 infection among the health care workers. Coronaviruses. 2021. doi:10.2174/2666796702666210216143134

83. Business Today. Coronavirus in UK: Boris Johnson admitted to hospital for testing positive; 2020. Available from: https://www.busi nesstoday.in/current/world/coronavirus-in-uk-boris-johnson-admitted -to-hospital-for-testing-positive/story/400221.html. Accessed April $10,2020$.

84. Rume T, Islam SD. Environmental effects of COVID-19 pandemic and potential strategies of sustainability. Heliyon. 2020;6(9):e04965.

85. Pal RK, Naik G, Rathore V, Sahu KK, Kumar R. Comparison between two different successful approaches to COVID-19 pandemic in India (Dharavi versus Kerala). J Family Med Prim Care. 2020;9 (12):5827-5832. PMID: 33681002; PMCID: PMC7928144. doi:10.4103/jfmpc.jfmpc_1860_20

86. COVID-19 vaccine tracker and landscape. Available from: https:// www.who.int/publications/m/item/draft-landscape-of-COVID-19candidate-vaccines. Accessed July 21, 2021.

87. Sharma D. Repurposing of the childhood vaccines: could train the immune system against the SARS-CoV-2. Expert Rev Vaccines. 2021. doi:10.1080/14760584.2021.1960161

88. The effects of virus variants on COVID-19 vaccines. WHO; 2021. Available from: https://www.who.int/news-room/feature-stories /detail/the-effects-of-virus-variants-on-COVID-19-vaccines?gclid= EAIaIQobChMIge68zrva8AIVjgkrCh29ewUxEAAYASAAEgJMSv D_BwE. Accessed July 21, 2021.

89. Available from: https://thefederal.com/news/government-issues-dosand-donts-for-mucormycosis-in-covid-19-patients/. Accessed July $21,2021$.
Research and Reports in Tropical Medicine

\section{Publish your work in this journal}

Research and Reports in Tropical Medicine is an international, peerreviewed, open access journal publishing original research, case reports, editorials, reviews and commentaries on all areas of tropical medicine, including: Diseases and medicine in tropical regions; Entomology; Epidemiology; Health economics issues; Infectious disease; Laboratory science and new technology in tropical medicine;

\section{Dovepress}

Parasitology; Public health medicine/health care policy in tropical regions; and Microbiology. The manuscript management system is completely online and includes a very quick and fair peer-review system. Visit http://www.dovepress.com/testimonials.php to read real quotes from published authors. 